steel during ion nitriding. Eastern-European Journal of Enterprise Technologies, 2 (5 (80)), 45-49. doi: 10.15587/17294061.2016.65454

12. Kostyk, K. O. (2013). Zmicnennja pres-form lyttja pid tyskom po nanotehnologii'. Mashynobuduvannja, 12, 113-118.

13. Bidulja, P. N. (1961). Tehnologija stal'nyh otlivok. Metallurgizdat, 352.

14. Domin, D. A. (2013). Artificial orthogonalization in searching of optimal control of technological processes under uncertainty conditions. Eastern-European Journal of Enterprise Tech- nologies, 5 (9 (65)), 45-53. Available at: http://journals.uran.ua/ eejet/article/view/18452

15. Domin, D. A. (2013). Mathematical modeling in the problem of selecting opti-mal control of obtaining alloys for machine parts in un-certainty conditions. Problems of mechanical engineering, 16 (6), 15-23. Available at: http://journals.uran.ua/ jme/article/view/21309/36478

16. Domin, D. A. (2011). Methodology of forming functional in the optimal control electric smelting. Technology audit and production reserves, 1 (1 (1)), 15-24. Available at: http://journals.uran.ua/tarp/article/view/4082/3748

Рекомендовано до публікачії д-р техн. наук, професор Хорошилов О. М. Дата надходження рукопису 12.05.2016

Радченко Александр Алексеевич, кандидат технических наук, ПАО «Харьковский Тракторный Завод им. С. Орджоникидзе», пр. Московский, 275, г. Харьков, Украина, 61007

Алексеенко Юлия Николаевна, кафедра литейного производства, Национальный технический университет «Харьковский политехнический институт», ул. Багалея, 21, г. Харьков, Украина, 61002 E-mail: litvo11@kpi.kharkov.ua

Чумаченко Виталий Иванович, кафедра литейного производства, Национальный технический университет «Харьковский политехнический институт», ул. Багалея, 21, г. Харьков, Украина, 61002

Богдан Виктория Владимировна, кафедра литейного производства, Национальный технический университет «Харьковский политехнический институт», ул. Багалея, 21, г. Харьков, Украина, 61002

\title{
УДК 621.74
}

DOI: $10.15587 / 2313-8416.2016 .69970$

\section{ОПТИМИЗАЦИЯ ПРОЦЕССА ТЕПЛОВОЙ СУШКИ ЖИДКОСТЕКОЛЬНОЙ СМЕСИ ПО КРИТЕРИЮ ПРОЧНОСТИ НА РАЗРЫВ}

\author{
(C) П. С. Зинченко, В. В. Голиньков, С. А. Старых, М. А. Ступар
}

Выполнено математическое моделирование процесса тепловой сушки омагниченной жидкостекольной смеси. Показано, что в исследованной области входных переменных - напряженности магнитного поля и времени сушки, оптимальные параметры проиесса составляют 143493A/м и 5 мин соответственно. При таких значениях параметров имеется принципиальная возможность повышения прочности образияа на разрыв до 3,2 кг/см²

Ключевые слова: напряженность магнитного поля, смесеприготовительное отделение, жидкостекольная смесь

Mathematical simulation of thermal drying of magnetized liquid glass mixture is done. It is shown that in the investigated range of input variables - magnetic field strength and drying time, the optimum process parameters are $143493 \mathrm{~A} / \mathrm{m}$ and $5 \mathrm{~min}$ respectively. Principal possibility of increasing the tensile strength of the sample up to $3.2 \mathrm{~kg} / \mathrm{cm}^{2}$ is observed under such values of the parameters

Keywords: magnetic field strength, mixture preparation section, liquid glass mixture

\section{1. Введение}

Современные тенденции в области развития литейного производства таковы, что на первое место выходят разработки, связанные с созданием компьютерно-интегрированных технологий, в основе которых лежит оптимизация конструкторско-технологической подготовки производства. В отличие от предшествующих подходов к освоению технологий новых отливок, характерных для производства XX века, современные подходы предполагают параллельное решение вопросов проектирования и технологиче- ского воплощения проектных решений в жизнь. Это стало возможным благодаря использованию $\mathrm{CAD} /$ CAM/CAE-систем, однако базируется это на понимании того, что без согласованности конструкторской разработки и технологических возможностей нельзя получить высококачественную отливку $[1,2]$. Т. е. несоответствие технологических возможностей конструкторскому решению (проекту) приводит к получению отливок, не удовлетворяющих тем или иным требованиям. И тут на первое место выходит человеческий фактор - отсутствие современных средств 
АСУ ТП приводит к значительному влиянию субъективизма в технологическом процессе изготовления отливок. Поэтому вопросы, связанные с внедрением систем автоматизации, являются актуальными и, в первую очередь, нужно говорить об алгоритмах работы этих систем применительно к условиям украинских литейных цехов, а также об адекватном математическом их обеспечении.

\section{2. Анализ литературных данных}

Специфические условия украинских литейных цехов состоят в том, что на формовочных участках практически повсеместно используются встряхивающие или встряхивающе-прессовые машины, работающие со смесями на жидком стекле. Известные проблемы с относительно невысоким качеством поверхности отливок, вызванные применением таких смесей, да еще плохая выбиваемость, ставят перед исследователями задачи улучшения таких смесей, направленные в основном снижение содержания жидкого стекла, использования специальных отвердителей [3] или технологий обработки жидкого стекла или смесей на его основе [4-5]. Применяемые методы планирования эксперимента [6] или их разновидности для случаев, когда нет возможности осуществлять точный контроль наиболее важных технологических параметров [7], позволяют получать регрессионные уравнения для дальнейшего поиска оптимальных технологических режимов. Использование их обеспечивает улучшение качества процессов уплотнения [8] и позволяет формировать условия для модернизации существующих машин внедрением современных систем управления, позволяющих оптимизировать процесс по выбранным критериям качества $[9,10]$. Применение таких решений может в некотором роде составить конкуренцию внедряемым в современных цехах ХТС-процессам, основанным на использовании смесителей непрерывного действия и смесей специальных составов $[11,12]$. В таком направлении перспективным может быть разработка математических моделей, позволяющих решать задачу оптимизации технологических режимов обработки жидкого стекла или смесей на его основе. В случае если не все техно- логические параметры, являющиеся входными переменными, подлежат контролю, возможна нечеткая их кластеризация и определение выходной переменной (качество получаемой смеси) в зависимости от функций принадлежности $(L-R)$ типа [13].

\section{3. Цель и задачи исследования}

Целью работы являлся получение математической модели для последующей оптимизации технологии обработки жидкостекольных смесей.

Для достижения поставленной цели решались следующие задачи:

- исследовать влияние технологических режимов тепловой сушки смесей;

- определить возможные направления оптимизации режимов сушки.

4. Методика исследования и результаты математического моделирования тепловой сушки жидкостекольных смесей

В качестве экспериментального материала выбраны результаты промышленных исследований процесса омагничивания жидкого стекла [14], не нашедшие развития в плоскости математического моделирования и последующей оптимизации (табл. 1).

В качестве входных переменных выбраны напряженность магнитного поля $\left(\mathrm{x}_{1}\right)$ и продолжительность тепловой сушки $\left(\mathrm{x}_{2}\right)$, предварительно нормированные до диапазона $(-1 ;+1)$ в соответствии с [8]. Границы плана пассивного эксперимента выделены в табл. 1. двойной линией. Видно, что план является ортогональным, поэтому возможно получение оценок коэффициентов уравнения регрессии по простым зависимостям $[4,8]$. Расчет коэффициентов математической модели выполнялся в среде электронных таблиц Excel:

$$
\begin{aligned}
& y=2,189+0,25 x_{1}+0,07 x_{2}-0,35 x_{1}^{2}- \\
& -0,40 x_{2}^{2}-5,6 \times 10^{-17} x_{1} x_{2} .
\end{aligned}
$$

На рис. 1 показана поверхность отклика, описывающая полученную математическую модель (1).

Таблица 1

Экспериментальные данные

\begin{tabular}{|c|c|c|c|c|c|c|c|c|}
\hline \multirow{2}{*}{$\begin{array}{c}\text { Напряженность } \\
\text { магнитного поля, } \\
\text { А/м }\end{array}$} & \multicolumn{7}{|c|}{ Продолжительность тепловой сушки при $200{ }^{\circ}$ в в мин } \\
\cline { 2 - 8 } & 30 & 50 & 60 & 90 & 120 & 150 & 180 \\
\cline { 2 - 8 } & 0,26 & 0,17 & 0,12 & 0,11 & 0,1 & 0 & 0 \\
\cline { 2 - 8 } & \multicolumn{7}{|c|}{ Прочность образца на разрыв, кг/см ${ }^{2}$} \\
\hline 25600 & 1,1 & 1,3 & 1,5 & 1,7 & 1,6 & 1,4 & 1,2 \\
\hline 77000 & 1,6 & 2,7 & 1,9 & 2,2 & 2,1 & 1,7 & 1,6 \\
\hline 127000 & 2,2 & 2,5 & 2,8 & 2,6 & 2,5 & 2,4 & 2,3 \\
\hline 175000 & 2,2 & 2,4 & 2,6 & 2,5 & 2,4 & 2,3 & 1,9 \\
\hline
\end{tabular}




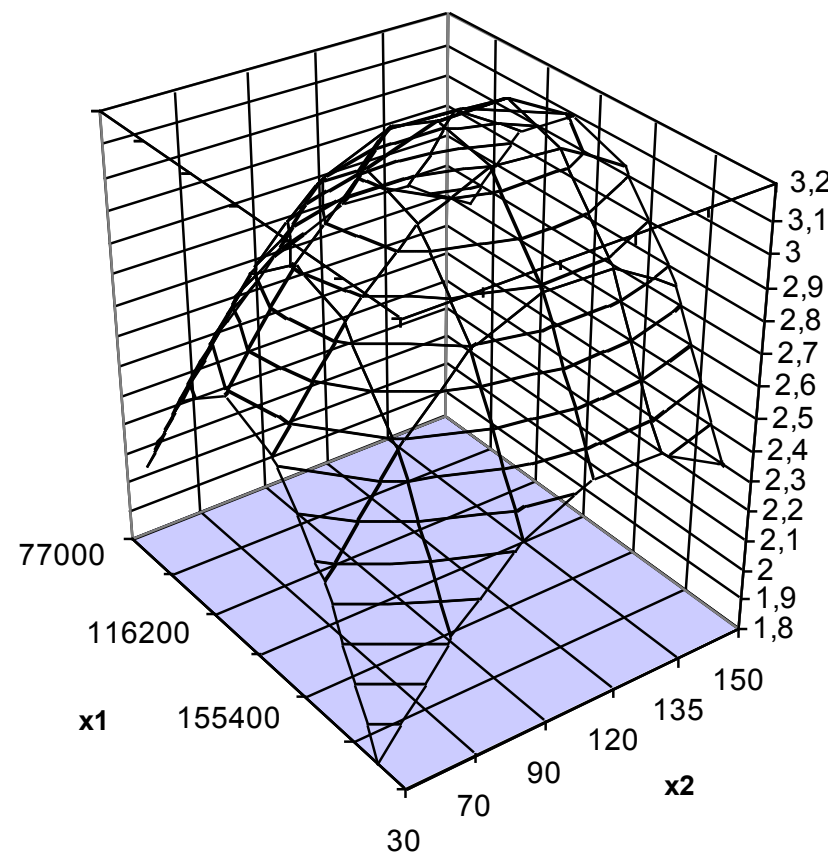

\author{
Прочность \\ образца на \\ разрыв, кг/см2
}

30

Рис. 1. Поверхность отклика, описывающая математическую модель зависимости прочности образца на разрыв от напряженности магнитного поля и продолжительности тепловой сушки

\section{5. Обсуждение результатов моделирования влияния технологических режимов на прочность образца}

Как видно из полученной модели, фактор совместного влияния входных переменных незначим и, следовательно, может быть исключен из математической модели. Т. к. план пассивного эксперимента является ортогональным, исключение одного члена из уравнения регрессии не вызовет необходимости пересчета всех остальных коэффициентов. Большее влияние на формирование прочности образца оказывает напряженность магнитного поля и влияние квадратичных эффектов от обоих факторов является значимым. Более того, план эксперимента фактически описывает оптимальную область, при этом имеется принципиальная воз-

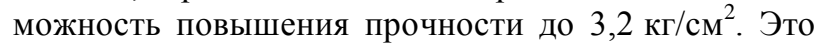
не противоречит выводам, сделанным в работе [14], согласно которым при изменении магнитного поля прочность проходит через максимум. Заметное повышение прочности, наблюдаемое при значениях модуля меньше 2, может быть связано с равновесным содержанием кремнезема и щелочи в жидком стекле, при котором имеется возможность перестройки диполей для омагниченного и неомагниченного стекла за счет электростатического состояния системы. При этом оптимальные значения технологических параметров, полученные исследованием модели (1) и пересчетом нормированных значений в натуральные, составляют: напряженность магнитного поля 143493 А/м, продолжительность тепловой сушки примерно 95 мин. Вероятным развитием исследования может быть выход за область планирования с целью проверки достижения глобального оптимума - либо преобразованием поверхности отклика к каноническому виду, либо проведением «ридж»-анализа [15].

\section{6. Выводы}

Полученная математическая модель в виде уравнения двухфакторной регрессии позволяет утверждать, что приоритетным фактором влияния на прочность образца, подвергнутого тепловой сушке с омагниченным жидким стеклом, является напряженность магнитного поля. Оптимальные технологические параметры процесса, полученные её аналитическим исследованием, могут быть принятыми такими: напряженность магнитного поля 143493A/м, продолжительность тепловой сушки примерно 95 мин.

\section{Литература}

1. Акимов, О. В. Анализ погрешностей формообразования отливок колес турбин турбокомпрессоров для наддува ДВС на этапе изготовления их восковых моделей [Текст] / О. В. Акимов // Восточно-Европейский журнал передовых технологий. - 2003. - № 3 (3). - С. 16-24.

2. Акимов, О. В. Анализ собственных колебаний отливки блок-картера дизеля “СМД” [Текст] / О. В. Акимов, Ю. П. Анацкий, В. А. Солошенко // Вестник Харьковского государственного политехнического университета. 1999. - № 66. - C. 40-47

3. Пономаренко, О. И. Влияние жидких отвердителей с разными добавками на свойства жидкостекольных смесей [Текст] / О. И. Пономаренко, Н. С. Евтушенко, Т. В. Берлизева // Литейное производство. - 2011. - № 4. C. 21-24.

4. Курын, М. Г. Определение оптимальных характеристик жидкого стекла для процесса омагничивания жидкостекольных смесей [Текст] / М. Г. Курын // Технологический аудит и резервы производства. - 2011. - Т. 2, № 2. C. 14-20. - Режим доступа: http://journals.uran.ua/tarp/ article/ view/4860/4511

5. Курын, М. Г. Синтез самотвердеющих смесей с заданным комплексом свойств и оптимизация технологических режимов их изготовления [Текст] / М. Г. Курын // Технологический аудит и резервы производства. - 2012. - Т. 1, № 3. - C. 25-29. - Режим доступа: http://journals.uran.ua/ tarp/article/view/4872/4523 
6. Пономаренко, О. И. Математические модели свойств для холоднотвердеющей смеси (XТC) на основе жидкого стекла [Текст]: межд. конф. / О. И. Пономаренко, Т. В. Берлизева // Литье: Промышленный инвестиционный форум. - Запорожская торгово-промышленная палата, 2011. - С. 150-151.

7. Дёмин, Д. А. Применение искусственной ортогонализации в поиске оптимального управления технологическими процессами в условиях неопределенности [Текст] / Д. А. Дёмин // Восточно-Европейский журнал передовых технологий. - 2013. - Т. 5, № 9 (65). - С. 45-53. - Режим доступа: http://journals.uran.ua/eejet/article/view/18452

8. Фролова, Л. В. Выявление резервов энергосбережения на основе технологического аудита работы формовочных встряхивающих машин [Текст] / Л. В. Фролова // Технологический аудит и резервы производства. - 2011. T. 2, № 2 (2). - C. 8-13. - Режим доступа: http://journals.uran. ua/tarp/article/view/4859/4510

9. Дёмин, Д. А. Методология формирования функционала для задачи оптимального управления электроплавкой [Текст] / Д. А. Дёмин // Технологический аудит и резервы производства. - 2011. - Т. 1, № 1 (1). - С. 15-24. - Режим доступа: http://journals.uran.ua/tarp/article/ view/4082/3748

10. Фролова, Л. В. Вибір шляхів вдосконалення конструктивних елементів формувальних струшуючих машин [Текст] / Л. В. Фролова // Технологический аудит и резервы производства. - 2012. - Т. 1, № 1(3). - С. 30-34. - Режим доступа: http://journals.uran.ua/tarp/article/ view/4873/4524

11. Евтушенко, Н. С. Исследование свойств регенерируемых смесей на основе ОФОС [Текст] / Н. С. Евтушенко, О. И. Шинский, О. И. Пономаренко // Компрессорное и энергетическое машиностроение. - 2013. - № 4. - С. 48-51.

12. Берлизева, Т. В. Влияние фурфурилоксипропилциклокарбонатов (ФОПЦК) с различными добавками на свойства холоднотвердеющих смесей на жидком стекле [Текст] / Т. В. Берлизева, О. И. Пономаренко, А. М. Каратеев, Д. А. Литвинов // Компрессорное и энергетическое машиностроение. - 2013. - № 3. - С. 26-29.

13. Дёмин, Д. А. Нечеткая кластеризация в задаче построения моделей «состав - свойство» по данным пассивного эксперимента в условиях неопределённости [Текст] / Д. А. Дёмин // Проблемы машиностроения. - 2013. - Т. 16, № 6. - С. 15-23. - Режим доступа: http://journals.uran.ua/ jme/article/view/21309/36478

14. Берг, Л. И. Омагничивание жидкостекольных смесей [Текст] / Л. И. Берг, Н. Х. Иванов, А. Л. Правошинский // Литейное производство. - 1972. - № 9. - С. 25.

15. Дьомін, Д. О. Деякі аспекти управління якістю чавуну з пластинчастим графітом [Текст]: дис.... канд. техн. наук [Текст] / Д. О. Дьомін. - Харків, 1995. - 181 с.

\section{References}

1. Akimov, O. V. (2003). Analysis of errors in formshaping of casts of turbo compressor turbine wheels for combustion engine supercharge at the stage of their wax models production. Eastern-European Journal of Enterprise Technologies, 3 (3), 16-24.
2. Akimov, O. V., Anackij, Ju. P., Soloshenko, V. A. (1999). Analiz sobstvennyh kolebanij otlivki blok-kartera dizelja "SMD". Vestnik Har'kovskogo gosudarstvennogo politehnicheskogo universiteta, 66, 40-47.

3. Ponomarenko, O. I., Evtushenko, N. S., Berlizeva, T. V. (2011). Vlijanie zhidkih otverditelej s raznymi dobavkami na svojstva zhidkostekol'nyh smesej. Litejnoe proizvodstvo, 4, 21-24.

4. Kuryn, M. G. (2011). Determination of optimum performance liquid glass of magnetization mixtures with liquid glass. Technology audit and production reserves, 2 (2), 14-20. Available at: http://journals.uran.ua/tarp/article/view/4860/4511

5. Kuryn, M. G. (2012). Synthesis of cold-hardening mixtures with given set of properties and optimization of technological regimes of their manufacturing. Technology audit and production reserves, 1 (3), 25-29. Available at: http://journals.uran.ua/ tarp/article/view/4872/4523

6. Ponomarenko, O. I., Berlizeva, T. V. (2011). Matematicheskie modeli svojstv dlja holodnotverdejushhej smesi (HTS) na osnove zhidkogo stekla. Lit'e: Promyshlennyj investicionnyj forum. Zaporozhskaja torgovo-promyshlennaja palata, 150-151.

7. Domin, D. A. (2013). Artificial orthogonalization in searching of optimal control of technological processes under uncertainty conditions. Eastern-European Journal of Enterprise Technologies, 5 (9 (65)), 45-53. Available at: http://journals.uran.ua/ eejet/article/view/18452

8. Frolova, L. V. (2011). Identification provision of energy saving on the basis of audit process moulding machines shaking. Technology audit and production reserves, 2 (2 (2)), 8-13. Available at: http://journals.uran.ua/tarp/ article/view/4859/4510

9. Domin, D. A. (2011). Methodology of forming functional in the optimal control electric smelting. Technology audit and production reserves, 1 (1(1)), 15-24. Available at: http://journals.uran.ua/tarp/article/view/4082/3748

10. Frolova, L. V. (2012). Choice of ways to improve design elements of machines moulding shaking. Technology audit and production reserves, 1 (1(3)), 30-34. Available at: http://journals.uran.ua/tarp/article/view/4873/4524

11. Evtushenko, N. S., Shinskij, O. I., Ponomarenko, O. I. (2013). Issledovanie svojstv regeneriruemyh smesej na osnove OFOS. Kompressornoe i jenergeticheskoe mashinostroenie, $4,48-51$.

12. Berlizeva, T. V., Ponomarenko, O. I., Karateev, A. M., Litvinov, D. A. (2013). Vlijanie furfuriloksipropilci klokarbonatov (FOPCK) s razlichnymi dobavkami na svojstva holodnotverdejushhih smesej na zhidkom stekle. Kompressornoe i jenergeticheskoe mashinostroenie, 3, 26-29.

13. Domin, D. A. (2013). Mathematical modeling in the problem of selecting opti-mal control of obtaining alloys for machine parts in un-certainty conditions. Problems of mechanical engineering, 16 (6), 15-23. Available at: http://journals.uran.ua/ jme/article/view/21309/36478

14. Berg, L. I., Ivanov, N. H., Pravoshinskij, A. L. (1972). Omagnichivanie zhidkostekol'nyh smesej. Litejnoe proizvodstvo, 9, 25.

15. Domin, D. O. (1995). Dejaki aspekty upravlinnja jakistju chavunu z plastynchastym grafitom. Kharkiv, 181.

Рекомендовано до публікації д-р техн. наук, професор Хорошилов О. М. Дата надходження рукопису 18.05.2016

Зинченко Павел Сергеевич, главный металлург, ПАО «Свет Шахтера», ул. Свет Шахтера, 4/6, г. Харьков, Украина, 61001

Голиньков Владислав Владиславович, кафедра литейного производства, Национальный технический университет «Харьковский политехнический институт», ул. Багалея, 21, г. Харьков, Украина, 61002 E-mail: litvo11@kpi.kharkov.ua

Старых Сергей Александрович, кафедра литейного производства, Национальный технический университет «Харьковский политехнический институт», ул. Багалея, 21, г. Харьков, Украина, 61002

Ступар Максим Андреевич, кафедра литейного производства, Национальный технический университет «Харьковский политехнический институт», ул. Багалея, 21, г. Харьков, Украина, 61002 